\title{
LAS MUJERES CRIPTOJUDÍAS EN LA PRIMERA MITAD DEL SIGLO XVIII: RECUPERACIÓN HISTÓRICA E INQUISICIÓN ${ }^{1}$
}

\author{
Sonia Pérez-Villanueva \\ Universidad de Lesley - Cambridge, MA, EE.UU. \\ sperezvi@lesley.edu
}

De los doze relapsos en su culpa,

Ocho mugeres son: ¿Quién tal creyera?

Pues se opone a lo débil de su sexo,

Tanta perseverancia, y subsistencia.

Anónimo (1723), Poema Heroyco, Granada.

【

a persecución de la Inquisición contra culturas criptojudías durante la primera mitad del siglo XVIII ha sido objeto de diferentes estudios que han aportado importantes contribuciones sobre el tema, siendo en su mayoría estudios históricos con contenido documental que se centran en zonas geográficas específicas (Caro Baroja 1978; Kamen 1979; Llorente 1980; Domínguez Ortiz 1988; Lera García 1987 y 1989; Peñafiel Ramón 1992; Prado Moura 1996; Martínez Millán 1989 y 2000; Torres Arce 2000; Alpert 2001; Pérez de Colosía Rodríguez 2005; Buitrago González 2012, 2013 y 2014; Belinchón 2014; Madrigal Castro 2017). Gracias a dichos estudios y a la documentación recogida, podemos estimar que se celebraron 144 autos de fe entre 1700 y 1758 donde alrededor de 1.300 personas fueron castigadas por practicar la ley de Moisés. De estos 144 autos de fe, Alpert localiza los tribunales más activos en Granada (25 autos), Sevilla

\footnotetext{
$1 \quad$ Este artículo se ha desarrollado dentro del proyecto «La mujer frente a la Inquisición española y novohispana» (FEM2016-78192-P), I+D de Excelencia del Ministerio de Economía y Competitividad (MINECO), financiado por la Agencia Estatal de Investigación (AEI) y el Fondo Europeo de Desarrollo Regional (FEDER, UE); y del grupo de investigación «Mentalidades mágicas y discursos antisupersticiosos (siglos XVI, XVII y XVIII)», grupo consolidado por la Universidad Autónoma de Madrid.
}

Edad de Oro, XXXVIII (2019), pp. 197-215, ISSN: 0212-0429 - ISSNe: 2605-3314

DOI http://doi.org/10.15366/edadoro2019.38.010 
(19 autos), Córdoba (18 autos), Valladolid (16 autos), Toledo (15 autos) y Cuenca (12 autos), y destaca que también se llevaron a cabo juicios y autos, o autillos, en Murcia, Madrid, Barcelona, Llerena, Valencia, Zaragoza, Logroño, Santiago y Palma de Mallorca (187-199). A pesar de la abrumante presencia de mujeres en estos procesos inquisitoriales del siglo XVIII, dichos estudios apenas las mencio$\mathrm{nan}^{2}$. Consideramos por ello importante estudiar el papel de las mujeres criptojudías en el contexto histórico de la primera mitad del siglo XVIII para poder indagar las razones por las que la Inquisición las consideró como su principal amenaza y objetivo de persecución. En un principio, se dará un breve contexto político-cultural de las primeras décadas del siglo XvIII para entender el porqué del despertar del acoso inquisitorial contra culturas criptojudías. De ahí, se destacará la importancia de las mujeres en culturas criptojudías, para luego pasar al estudio de los autos de fe, la presencia de las mujeres en dichos procesos y el poder propagandístico de las publicaciones de los autos de fe en forma de relaciones.

Después de la muerte de Carlos II en noviembre de 1700, las distintas dinastías de Europa quisieron apoderarse del trono español, a pesar de que el último monarca de los Austrias había dejado un testamento antes de morir donde nombraba a su heredero, Felipe, duque de Anjou, nieto del rey francés Luis XIV, como rey de España. La Guerra de Sucesión (1701-1713) sumergió a España en una profunda crisis que continuaría el declive de la última década del siglo XVII, caracterizado por desastres naturales, hambruna, pestes y guerras. El tribunal de la Santa Inquisición, unido en su mayoría al frente borbónico, comenzó asimismo una fase de decadencia que le impidió ejecutar su actividad de persecución realizada desde sus orígenes en 1478 (Galende Díaz 1988: 245) . Efectivamente, coincidiendo con la Guerra de Sucesión, el Santo Oficio vivió «el período más oscuro de toda la historia de la Inquisición española» (Egido 1984: 1.227). En una España devastada y dividida como resultado de la ocupación de las fuerzas aliadas, por un lado, y la misión de reconquista del rey Borbón por otro, el Santo Oficio perdió su poder económico y cultural. La crisis del país impidió que los tribunales locales de la Inquisición pudiesen recaudar ingresos, lo cual contribuyó a la existente crisis de la institución que ya apenas tenían recursos y carecía de personal. Todo ello paralizó la actividad del Santo Oficio que claramente dependía de la condición general de la economía del país para subsistir (Haliczer 1990: 330-358). La restauración de

2 Estimamos un $65 \%$ de mujeres castigadas por judaizantes particularmente en los autos de fe de 1720 a 1733.

3 La Guerra de Sucesión en España presentó también problemas de lealtad para la Inquisición, que acabó dividiéndose y debilitándose durante los años de conflicto. Ver Egido (1984: 1.227-1.233) donde se desglosa la complejidad de la división inquisitorial en zonas de apoyo carlista (apoyando al archiduque Carlos de Austria) o borbónico (en apoyo de Felipe V). 
la paz en 1713 y la estabilidad política construida por Felipe V y sus aliados promovieron planes para la futura recuperación económica. La relación Corona-Inquisición que, durante los siglos anteriores había sido de unidad, se desequilibró con la Guerra de Sucesión. Sin embargo, las relaciones cobraron fortaleza gracias a la llegada de Isabel de Farnesio como segunda mujer de Felipe V (1714), quien motivó cambios importantes en la corte, como el relevo de influyentes consejeros conversos de origen portugués, la destitución del inquisidor general Giudice, o el proceso del antiguo fiscal del Reino, Melchor Rafael de Macanaz, promotor de una propuesta de reforma del Santo Oficio (Madrigal Castro 2017: 139). El nombramiento por parte del propio Felipe V del obispo de Pamplona, Juan de Camargo, como inquisidor general, el 23 de agosto de 1720, supuso el afianzamiento de unidad y lealtad de la Inquisición hacia la Corona.

En su intento de hacer resurgir la economía española, Felipe V y sus consejeros recurrieron, entre otros, al monopolio del tabaco, así como del control absoluto de las rentas. La administración borbónica vio en el negocio tabaquero el impulso que estaban esperando para contribuir, entre otras actividades, a la economía de la Corona. Sin embargo, la renta de las tabacaleras llevaba ya tiempo en manos de judíos conversos, particularmente de migrantes procedentes de Portugal que llegaron al país a partir de la unificación de la península en 1581. A pesar de la cultura antisemita y antiportuguesa de la España del siglo xvi y de la constante amenaza de la Inquisición, muchas familias lusas se asentaron en España, creando negocios relacionados con la medicina, el comercio de tejidos, finanzas, banca, recaudación de impuestos y rentas de tabacaleras, entre otros (López Belichón 2014: 6). Desde la implantación del estanco de tabaco en 1636 en España, la Corona dejó en manos de hombres de negocios la administración de la renta tabacalera, sucediéndose de manera hereditaria a través de generaciones de familias luso conversas ya asentadas en España (Rodríguez Gordillo 2002: 277-282). Cuando el hombre de negocios fallecía, su viuda heredaba el negocio y se encargaba del arrendamiento, siempre y cuando no volviese a casarse. De esta manera, las familias conversas, tanto hombres como mujeres, consiguieron un control absoluto del negocio tabaquero hasta el 1 de septiembre de 1731, fecha en que se puso en vigor la Real Cédula del 9 de abril de 1701, en la que se otorgaba la completa administración del tabaco y sus rentas a la Hacienda del Estado. La cédula se basaba en «los detrimentos que sufría la renta por los fraudes que cometían los arrendadores», culpando a las familias conversas de la crisis que sufría el país. El decreto se vio apoyado por el economista Francisco Máximo de Moya Torres y Velasco, quien en su manifiesto antisemita declaraba que:

Muchísimo judaísmo se encierra en España, sin embargo, del infatigable zelo con que dicho Santo Tribunal vigila, como tiene manifestado en sus inquisiciones, y 
repetidos numerosos Autos de Fe que celebra [...]. Es el ordinario vivir de estos, Señor, el logro, la usura, sus ejercicios médicos, renteros, mercaderes, confiteros, y todos sus oficios son de araganes: son mañosísimos, y astutos; y cuando renteros que están con poderlo, tiranos, y se vengan de la sangre cristiana [...] y como estos no van diciendo que son judíos, ni llevan señal de tales, y son fingidos en la devoción que siempre manifiestan, y buenas palabras que practican (que fuera mejor fuesen las obras buenas, aunque las palabras no fuesen tales) son tenidos por piadosos, y liberales, y todo es artificio del engaño: con que logran caudales muy opulentos, que también echan fuera de España, para luego tener refugio en ellos, y los remiten a la Berberia, Argel, Liorna, y a otras partes, donde tiene juderías (1992: 296-297).

La afluencia económica de algunas familias durante momentos de crisis exacerbó una relación ya tensa entre los supuestos cristianos viejos y las familias de judíos conversos, quienes terminaron siendo víctimas de reacciones violentas y se convirtieron en chivos expiatorios de una trama financiera. Como critica De Moya Torres y Velasco en su tratado propagandístico, en el siglo XVIII, a los judíos conversos no se les obligaba a llevar vestimenta específica como había ocurrido en siglos anteriores y únicamente se les reconocía por sus «opulentos caudales». El mensaje antisemita del tratado contribuyó a la campaña de la Corona y de la Inquisición, quienes se valieron de la paranoia, el antisemitismo y la xenofobia existentes en la sociedad española para confiscar las pertenencias de familias conversas. Independientemente de los rituales privados que ciertas familias criptojudías pudiesen practicar, las acusaciones y los autos de fe fueron más allá de la religión y se basaban en envidias y recelos. Estos son los mecanismos por los cuales la Inquisición y la Corona despojaron a las familias criptojudías de sus pertenencias en España, revelando en las sentencias la estrecha relación entre el robo y el sacrificio. La persecución económica tomó la forma de procesos inquisitoriales o autos de fe, que condenaban a familias de practicar judaísmo con penas extremas como quema en la hoguera u otras condenas como cárcel, vergüenza pública, azotes, hábito, etc. No es sorprendente, sin embargo, que todos los acusados y acusadas tuviesen en común, de una manera u otra, la exclusión forzada de la economía familiar, ya que la Inquisición y, por extensión, la Corona, se apoderó de todos los bienes de dichas familias, con la sentencia de «confiscación de bienes». Efectivamente, en la primera mitad del siglo XVIII, después de una época de entumecimiento, el robo fue el catalizador del abuso antijudío y xenófobo provocado por la Inquisición, acelerando la progresión de la persecución a la invisibilidad y desaparición en masa. No es sorprendente que las víctimas de las Inquisición apodasen a la institución como «la pincha», los ladrones, que como ya apunta Caro Baroja, se trataba de una «alusión clara, sin duda, a los dineros que sacaban de cada proceso» (1978: 56). Las mujeres, responsables de adoctrinar a sus familias 
en las costumbres judaicas, fueron víctimas de este robo y sancionadas con dureza, reflejando una imagen de castigo público hacia las mujeres criptojudías que sirvió como herramienta propagandística principal. Las mujeres fueron el objetivo principal de la Inquisición porque se habían transformado, desde la conversión forzosa, en líderes religiosos y culturales y, en muchos casos, incluso llevaban el control de la economía familiar.

Desde los disturbios antijudíos de 1391 en Castilla y Aragón, donde fueron destruidas instituciones judías sagradas y cientos de judíos y judías fueron asesinadas y muchas otras fueron obligadas a la conversión, se formó una visión de que el centro del mundo criptojudío estaba dentro de la casa. El hogar judío converso era ese espacio doméstico donde las mujeres se transformaron en las rabinas que transmitirían su fe, rituales y tradiciones. La casa también llegó a ser vista como el espacio de reunión para conocer a otros «conversos» que mantenían sus tradiciones judaicas en secreto. Como consecuencia, el Santo Oficio vio una amenaza particular en las mujeres conversas, ya que se las consideraba portadoras de la fe del judaísmo después de la expulsión de los judíos en 1492. Además, después de la quema y destrucción de las sinagogas en España, la casa fue vista como un nuevo lugar de culto para los criptojudíos (Levine Melammed 1999: 3), como la sinagoga doméstica, el lugar seguro de la oración y la devoción. La toma de posesión de las propiedades de estas familias, de sus casas, por parte de la Inquisición, fue, por lo tanto, una destrucción simbólica de la sinagoga, que a su vez simbolizaba el judaísmo.

Una vez condenadas por la Inquisición, las mujeres que sobrevivían a la sentencia eran en su mayoría enviadas a iglesias u hospitales para su conversión forzosa y tras un periodo de tiempo, eran finalmente expulsadas de las «ciudades principales» sin ninguna pertenencia debido a la confiscación de bienes. Consecuentemente, las mujeres criptojudías se convirtieron en personas marginales, en despojos de la sociedad. La amenaza era tal que la Inquisición se valió de artes propagandísticas para enviar su mensaje antisemita a las ciudades más importantes de España y las Américas. Se hizo a través de publicaciones de relaciones de autos de fe, circulaciones sensacionalistas que llevaban los autos de fe «privados», los autillos de los templos, a grandes audiencias. Para Llorente, este cambio radical en la práctica de la Inquisición se debe al «corazón humano, compasivo y benéfico» de los inquisidores que, influenciados por el progreso del Siglo de las Luces, «adoptaron principios de moderación desconocidos en tiempos de los reyes austriacos» (1980: 85). Esta visión romántica de las actividades del Santo Oficio durante el siglo XVIII contrasta con la realidad económica de la época. Es cierto que, como ya ha apuntado Egido, «todas las contradicciones inherentes a la esencia y circunstancias de la Inquisición saltan en el siglo xviII», tiempo de declive para el Santo Oficio (Egido 1984: 1.204). Sin embargo, en época de crisis, el 
espectáculo del castigo de la Inquisición después del autillo se celebraba en la calle, donde las masas podían disfrutar de la vergüenza pública de las víctimas, que eran asesinadas en la hoguera, en el garrote, azotadas o, en muchos casos, vestidas en hábito para reconocimiento público.

Indudablemente, el contexto de Europa del Siglo de las Luces pone a España en el punto de mira. Intelectuales españoles y europeos criticaban las crueldades de la Inquisición y rechazaban el brutal comportamiento de los autos de fe públicos. La Inquisición decidió mantener los autos en espacios más privados y la monarquía dejó de asistir a ellos. Sin embargo, tal y como ya apunta Rafael de Lera García:

Durante el siglo XVIII no se realizaron autos de fe generales debido a los elevados gastos que suponían para las arcas inquisitoriales y a que la Inquisición perdió poder. Se llevaron a cabo, en cambio, autos de fe particulares también llamados autillos. Estos eran de menor entidad ya que no se realizaban en plazas públicas con gran pompa, sino que se hacían en el interior de iglesias o en el propio tribunal (1987: 153).

Es decir, que la intimidad de los autos de fe se debe a un asunto financiero más que a un asunto de cierta (y cuestionable) evolución cultural.

Investigadores expertos en la historia del judaísmo en España han localizado la génesis del despertar antisemita y la persecución en masa de la primera mitad del siglo XVIII en Madrid, en dos casos en particular. El primero nos lleva a 1718, con el proceso de una familia de origen portugués, Diego López de Castro Paz Coronel Quirós y sus hermanas Beatriz, María Antonia y Ángela de Quirós acusados de judaizantes (AHN, Inq., leg. 160, exp. 11; Caro Baroja 1978: III, 55-89; Blázquez Miguel 1988: 77; Lera García 1987: 151; Alpert 1997: 142) Beatriz, María Antonia y Ángela acostumbraban a visitar la casa de Manuela Pimentel y María Pimentel, vecinas de Madrid, que también estaban acusadas de prácticas judaicas (AHN, Inq., leg. 135, exp. 4). El proceso de Diego López de Castro Paz Coronel Quirós consta del testimonio central de Antonio Rodríguez Carrasco, preso en la cárcel por bigamia, quien acusó a más de cien personas residentes en Madrid de practicar judaísmo. Según Antonio Rodríguez Carrasco, María de Tudela, presa en la misma cárcel que él por judaizante, le brindó toda la información mientras ella paseaba por los pasillos de las celdas por «razones médicas». Es importante matizar que María de Tudela llegó embarazada a la cárcel donde dio a luz a un bebé que fue llevado inmediatamente a la inclusa para ser dado en

$4 \quad$ El padre de Diego López de Castro Paz Coronel Quirós y sus hermanas procedía de Portugal y emigró a Pontevedra donde se estableció y cambió de apellidos por miedo a represalias de los españoles. 
adopción. Los celadores le permitieron andar entre los pasillos de las celdas para poder aliviar su dolor tras el parto. De ahí que se encontrase con la celda de Antonio Rodríguez Carrasco y que supuestamente entablase conversación al comunicarle Antonio que él también era «observante» de la ley de Moisés (f. 10r). Seguidamente, María de Tudela, según la narrativa de Antonio Rodríguez Carrasco, supuestamente compartió información sobre otros cientos de familias criptojudías en la zona. La historia resulta en sí inverosímil, pero lo más sorprendente del caso es la «memoria» de Antonio Rodríguez Carrasco al recordar a pie juntillas toda la narrativa de su compañera de cárcel. En 30 folios de testimonio, Antonio Rodríguez Carrasco provee los nombres, apellidos y direcciones de todos los acusados, así como sus delitos de prácticas judías, tales como ponerse ropa limpia la víspera del sabbat, ayunar en días de fiesta, rechazar alimentos prohibidos (conejos, anguilas, salchichas y tocino), orar antes de las comidas, por la mañana y por la tarde, cubrirse la cabeza para el rezo e incluso realizar actos sacrílegos (f. 10r-47v).

Si bien es verdad que el temor de ser perseguido provocó peleas entre los judíos conversos y portugueses que vivían en España y se volvieron los unos contra los otros para demostrar su «verdadera» conversión al cristianismo, el distinguido estatus socio-económico de las familias acusadas resulta más que sospechoso (Caro Baroja 1978: 55-78) ${ }^{5}$. Algunas de las familias imputadas fueron asimismo relacionadas con personas influyentes en círculos cercanos a la Corona antes de los cambios impulsados por Isabel de Farnesio, tales como Melchor Rafael de Macanaz y la Princesa de los Ursinos. En efecto, este renacer del exterminio sistemático de familias criptojudías refleja el plan de persecución económica y expoliación a manos del Santo Oficio, apoyado por la Corona. Por otro lado, es importante observar que la culpa del testimonio original cae en una mujer, María de Tudela, viuda y madre de dos hijos, ambos llevados a la inclusa. No conocemos el testimonio de María de Tudela de primera mano y, por ello, no podemos entrar en detalles de su posible estado de vulnerabilidad y desesperación por sobrevivir. Aun así, podemos concluir que María de Tudela representaba una amenaza hacia la Inquisición por ser, ante todo, mujer y por haber sido instruida en la fe de Moisés por su madre, Luisa del Valle, y por su tía, Leonor del Valle, reflejando así el poder religioso y cultural de las mujeres criptojudías. Se puede decir que María de Tudela se convierte en una víctima más del plan de radicalización de la Inquisición para llevar a cabo un asalto a gran escala de las propiedades y bienes de familias criptojudías.

El otro caso importante que ha contribuido al resurgir de la actividad antisemita incluye curiosamente el círculo femenino que instruyó a María de Tudela y se

\footnotetext{
5 La narración de Antonio Rodríguez Carrasco refleja familias de posición social acomodada con profesiones que varían entre mercadería, medicina, administración de la renta de tabaco, banca, préstamo y negocios variados (ff. 12r-21v).
} 
centra en el supuesto descubrimiento de una sinagoga secreta en Madrid, en la que, como señala Roth, «durante algunos años, solían reunirse veinte familias para celebrar actos religiosos dirigidos por un guía espiritual» (1979: 242). En la relación del auto de fe del 7 de abril de 1720, encontramos a una mujer que podría encajar en la descripción de ese posible guía espiritual: Leonor Díaz . Sabemos que Leonor Díaz era natural de Madrid y que en 1720 contaba con 79 años. Fue condenada por ser «observante de la ley de Moisés y en ella instruyó a su familia y a muchos. Fue sentenciada a relajación al brazo seglar y fue quemada habiéndola dado garrote» (3). Efectivamente, la mujer anciana criptojudía, la matriarca de la familia, se convierte en el principal objetivo de la Inquisición ya que es ella quien transmite, desde su casa, la fe de Moisés. Ciertamente, el mensaje propagandístico del Santo Oficio define a las mujeres judías ancianas, y en su gran mayoría viudas, como la gran amenaza contra la Cristiandad. Leonor Díaz es un ejemplo de la mujer judía «reconocida», que como otras víctimas ancianas se describe como grotesca, con ropa vieja y sucia y con los brazos estropeados por los tormentos (Caro Baroja 1978: 57).

Tras la sentencia de Leonor Díaz, el Santo Oficio encuentra, acusa y enjuicia a sus cómplices, como Luisa del Valle, de 49 años, observante de la ley de Moisés, «quien instruyó a su familia y a muchos. Fue relajada al brazo seglar y quemada, habiéndola dado primero garrote» (3). Sospechamos que Luisa del Valle es la madre de María de Tudela a quien instruyó en la ley de Moisés. También acusaron a «Leonor María de Yuste, natural de esta corte, al parecer, nieta de Leonor Díaz» (4). El caso de Leonor María de Yuste es el más extraordinario ya que se nos dice que «se echó ella misma viva al brasero, mostrando en el auto el gozo que tenía ella misma de ir a morir en su fe» (5). Este elemento sensacionalista y malévolo del auto coincide con el componente espectacular del imaginario colectivo sobre «la mujer caída» judía, quien se lanzaría en la hoguera «con gozo». La elección de la palabra «gozo» no es fortuita; es perversa en boca del verdugo quien ofrece un imaginario de la mujer joven judía a una audiencia que goza de su muerte, «la posee y la disfruta», siguiendo la definición de gozo según el diccionario de Covarrubias. Esta sensualidad inicua coincide con el imaginario cristiano de las mujeres judías representadas en el arte bíblico español durante el Renacimiento y el Barroco ya que son típicamente jóvenes y hermosas, pero también se presentan con un sentido de degradación. Estos retratos reflejan mujeres sensuales, vestidas con ropas

$6 \quad$ Al final del auto de fe se dice que buscaban a un líder espiritual cuyo nombre se envió a Liorna donde fue aprobado. En el testimonio de Francisco de Torres se localiza la sinagoga en la casa de Francisco de Córdoba, el «rabino principal de España» elegido por la asamblea de Liorna. Fuera de España, donde las prácticas judaicas se podían seguir más libremente, eran los hombres y solo los hombres los que podían ser rabinos. En España la situación era diferente y la sociedad criptojudía dependía del liderazgo de las mujeres (AHN, Inq., leg.186, exp. 3; Alpert 1997: 15354; Lera García 1988: 93). 
lujosas, adornadas con joyas caras, que seducen y engañan a los sujetos cristianos para que puedan cometer su acto pecaminoso. No es sorprendente, por ello, que la hija de la familia Carrillo acusada por Antonio Rodríguez Carrasco sea «muchacha muy bonita y bien alhajada» (Caro Baroja 1978: 57), o la hija de la familia de León y Contreras, también acusada, sea descrita como «una hermosa muchacha apodada "la Judigüela"» (Caro Baroja 1978: 62). El énfasis en la belleza de la mujer joven judía, exterminadora en el acto, pero visualmente dócil (Lipton 2008: 204), se convierte en un mensaje propagandístico de advertencia hacia la sociedad cristiana.

Después de las causas de los reos y reas sentenciadas a muerte en el auto, se exponen los delitos de otras reas, con veredictos más leves como, por ejemplo, el de Antonia Tudela, de 26 años que, según la relación, fue acusada de observar la ley de Moisés, de ayunar los días designados que tienen instituidos por dicha ley, de no comer tocino, ni carne asada, ni sangre, ni aves sofocadas y de rezar oraciones judías (10). Fue condenada a cárcel perpetua irremisible, san Benito de dos aspas y 200 azotes (10). Antonia Tudela era hija de Luisa del Valle y según la narrativa de la relación, ambas se reunían en casa de Leonor Díaz y Leonor Josepha Juste, posiblemente la sinagoga mencionada en el caso, donde traían bajo sus pies hostias sagradas que luego arrojaban al fuego, ultrajaban a Jesucristo y quemaban su efigie crucificada (10). Esta narrativa de sacrilegio de un crucifijo, así como de profanación de la hostia sagrada se remonta ya a la Baja Edad Media cuando únicamente los hombres judíos eran los culpables de la acusación de profanación (71). Como Miri Rubin ha observado:

Jewish women rarely appear as abusers of the host, and were often punished only by implication and by association with the guilt of their menfolk. When agency is imputed to them this takes the form of more innocent or simple-minded transgressions (1999: 76).

La profanación a manos de mujer no es un fenómeno nuevo en la historia española narrada por la Inquisición. En el auto de fe del 4 de julio de 1632 de Madrid, 42 reos y reas escucharon sus sentencias. El objetivo principal del juicio fue ofrecer una exhibición pública del castigo de ocho mujeres ${ }^{8}$ y sus familias de origen portugués que fueron acusadas de practicar judaísmo y profanar una imagen de Cristo en una de sus casas en la calle de las Infantas, cerca del centro de Madrid. Asimismo, la relación del 7 de abril de 1720 refleja la versión propagandística de

\footnotetext{
$7 \quad$ No hemos encontrado documentación de que María de Tudela tuviese una hermana y no hemos hallado información sobre el proceso de María de Tudela. Es por ello que nos inclinamos a pensar que Antonia Tudela podría ser María de Tudela (María Antonia Tudela).

8 Leonor Rodríguez, María Rodríguez, Guiomar Rodríguez, Isabel Núñez Álvarez, Beatriz Núñez, Beatriz Enríquez, Violante Méndez y Victoria Méndez.
} 
la narrativa antisemita del auto de fe de 4 de julio de 1632 al describir a las mujeres criptojudías como pecadoras activas que amenazan constantemente la estabilidad de la cristiandad. Evidentemente, este auto de fe refleja el castigo unilateral hacia la población conversa femenina que resultó ser un blanco fácil de la Inquisición para llevar a cabo su plan de expoliación. A partir de esta relación, la Inquisición encargó la publicación de las relaciones de los autos de fe que continuaron en gran número hasta 1733, año en que la economía española ya se había estabilizado y la actividad inquisitorial comenzaba a decaer. No es casualidad que 1733 también marcase el año de la muerte del inquisidor general Camargo.

Las más de mil personas procesadas por judaizantes en autos de fe durante este corto periodo de tiempo (1720-1733) es prueba de que Iglesia y Estado continuaron con su agresivo plan de ataques antisemitas durante esta década. El librero Isidro Joseph Serrete, portero de la congregación de San Pedro Mártir, obtuvo la licencia para publicar los autos de fe en formas de relaciones impresas que vendía en su librería de la calle de la Sartén, en el centro de Madrid. Las relaciones comenzaron a venderse como pliegos sueltos y dada su popularidad se crearon colecciones que se editaron en volúmenes que cubrían de 1721 a 1725 y de 1721 a 1731 (BNE, R/8560 y BNE R/2725) ${ }^{9}$. Las relaciones se publicaron a petición de los funcionarios del Santo Oficio que intentaron registrar y publicar estos eventos clave como medio de difusión para comunicar el mensaje público de la Inquisición. Fueron producidas y vendidas por una variedad de vendedores de libros, aparentemente para el consumo público. Las relaciones contienen los nombres de cada individuo, su edad, ocupación, ofensa y castigo, que a su vez variaba entre cárcel, destierro, azotes, hábito, galeras, relajación en persona o relajación en estatua ${ }^{10}$. Como ya se ha mencionado antes, para las personas acusadas de judaizantes el castigo de confiscación de bienes era una constante.

9 Ver obras abordadas en este trabajo para las relaciones sueltas que la autora consultó en la biblioteca Houghton de Harvard. También ver el impresionante cuerpo de materiales ofrecido de Sefarad, particularmente la exposición «100 impresos españoles sobre la Inquisición. Instrucciones, edictos, cédulas, relaciones de autos de fe y otros» $<$ http://server.knosys.es/sefarad_pdf/100_Impresos_espanoles_Inquisicion.pdf.pdf>, así como la transcripción y codificación de Alexandra Duttenhofer $<$ http://odont.info/coleccion-de-varios-autos-de-fe-celebrados-de-1721--1725.html $>$.

10 Las mujeres en las relaciones de los autos de fe, en su mayoría, eran definidas por su edad, su origen (portuguesas), su profesión y su estado (casadas, viudas, solteras). Sin embargo, hemos encontrado el curioso caso de Gabriel Méndez, acusado de judaizante y definido como marido de Leonor Piñeyro, «reconciliada que ha sido por este Santo Oficio» (1). Al dar información sobre la mujer de Gabriel Méndez, el auto ya culpa a la mujer de adoctrinar a su marido en tradiciones judaicas, reflejando el liderazgo de las mujeres en las comunidades criptojudías (Relación de los reos que salieron en el Auto Particular de Fe que celebró el santo oficio de la Inquisición de Granada el día veinte de junio de mil setecientos y veinte y tres, en el Convento de Nuestra Señora de la Merced, de Calzados, de dicha Ciudad). 
La relación del auto de fe celebrado en Granada, en la iglesia del Real Monasterio de San Jerónimo el 30 de noviembre de 1721, en particular, refleja las características mencionadas anteriormente, muestra la prevalencia de mujeres acusadas de judaizantes en estos autos y también refleja que las mujeres recibían los castigos más severos. La relación lista a sesenta personas, cincuenta y ocho de ellas acusadas de judaizantes mientras que las otras dos fueron acusadas la una de bigamia y la otra de hipócrita embustera. En total, veinte personas fueron condenadas a muerte, siendo trece mujeres. Ocho acusados fueron relajados en estatua por herejes judaizantes. De estos, tres mujeres, Beatriz de Fonseca, portuguesa, de 69 años, Ana Núñez de la Rosa, natural de Antequera, de 67 años y Blanca de Amezquita y Soria, de Granada, con 36 años, cuyos huesos fueron exhumados para relajarlos junto a su estatua. Doce personas fueron relajadas en persona, de las cuales once eran mujeres. Una vez más, este número de mujeres asesinadas por la Inquisición por judaizantes refleja el espectáculo público del castigo hacia este género, responsables del criptojudaísmo. Quizás el caso más cruel sea el de Leonor María Rodríguez Ocaña Navarro, natural de Antequera y vecina de Granada, que fue relajada en persona por hereje judaizante y quemada viva. Treinta y siete personas fueron reconciliadas por herejes judaizantes, siendo quince mujeres y veintidós hombres. Las mujeres eran o hijas o esposas de los prisioneros. A todos ellos se les confiscaron los bienes, condenados a hábito y cárcel por un tiempo, desde dos meses hasta cárcel perpetua. Únicamente tres reos fueron condenados a azotes.

La portada de la Relación revela la iconografía propagandística del Santo Oficio utilizada para esta serie. Adornada con una orla tipográfica, el frontispicio ofrece la ilustración del escudo de la Inquisición xilográfico en el centro de la página. La estampa refleja una meticulosa estrategia ideológica del Santo Oficio ya que en la parte superior del clásico escudo inquisitorial con la espada (representando la justicia) y el ramo del olivo (representando la misericordia), encontramos la corona perfectamente encajada como si fuese parte del escudo en sí, simbolizando la unidad y harmonía entre Corona e Iglesia. Esto, por supuesto, contribuye al mensaje de que Camargo y Felipe V se encontraban aliados en su plan de recuperación económica a través de la explotación judía. Todas las relaciones consultadas para este estudio muestran en su portada este importante elemento iconográfico. Esta primera imagen de los textos se convierte en la marca que distingue las relaciones de otros tratados y las hace reconocibles al lector. Es importante recordar que la iconografía inquisitorial desde principios de la institución es mínima ya que se eligió de una manera estratégica para tener un efecto ideológico en la sociedad de su tiempo y más allá. La estrategia de marketing de las obras es extraordinaria también. Debajo del escudo, encontramos el nombre del inquisidor general, don Juan de Camargo, obispo de Pamplona, del Consejo de su Majestad y responsable de la actividad inquisitorial desde 1720, solo un año antes en que 
comenzaron las relaciones de Serrete. El impresor de esta relación en particular es Nicolás Rodríguez Francos, que como observa Agulló y Cobo, «mantenía un interesante comercio de libros con Venecia, y en 1723 envió treinta y tres cajones de libros sellados por la Inquisición con destino a Perú, Panamá y Buenos Aires» (1980: 19-20). De esta manera, se consiguió exportar el eficaz mensaje antisemita a Italia y a las Américas. En la parte inferior de la portada y dentro de la orla, como si se tratase de un cuadro, aparece el apunte «se hallará en la plazuela de la calle de la Sartén, en casa de Isidro Joseph Serrete, Librero y Portero de la Ilustre Congregación de San Pedro Mártir de Madrid». Las relaciones se promovían como un cuerpo de folletines mensuales a disposición de los lectores para que así pudiesen coleccionarlas. El póster anunciando los diferentes «números» de la colección [IMAGEN 1] demuestra este cruel objetivo.

La labor de promoción de estas relaciones es asombrosa. Cada relación publicada incluía el recordatorio de «se hallarán en la plazuela de la calle de la Sartén, en la librería de Isidro Joseph Serrete», bien en el frontispicio o al final de la obra. Protegido por la Inquisición, Serrete aprovechó los estrictos estatutos de producción y contenido que dominaban las publicaciones de la primera mitad del siglo XVIII para asegurar el éxito de su obra y atraer a los lectores a su librería.

Las estampas decorativas de los textos posiblemente se realizaron en varios talleres, bajo la dirección de impresores como Nicolás Rodríguez Francés, impresor madrileño o incluso Gabriel del Barrio, impresor de la Real Capilla de su Majestad. Las relaciones no incluyen ninguna referencia sobre la tipografía elegida, por lo que no podemos atribuir las ilustraciones y decoraciones a ningún ilustrador específico. Mientras que todas las relaciones incluyen la ilustración inicial del escudo, encontramos una curiosa ilustración al final de algunas relaciones [IMAGEN 2]. Así, la Relación del Auto de Fe celebrado en Sevilla el 14 de diciembre de 1721, por ejemplo, expone en su término una curiosa calcografía rectangular de tamaño 34 x $90 \mathrm{~mm}$. Se trata de una ilustración de un busto femenino con los pechos descubiertos y con los brazos arqueados que sostienen motivos vegetales entrelazados a ambos lados de la imagen. Encima de la cabeza se muestra una cesta o corona con frutas. El contenido simbólico de la imagen es impactante. Por un lado, los motivos fitomorfos en los brazos de la mujer, así como la fruta en la cabeza pueden representar la belleza, abundancia y prosperidad, elementos asociados a las familias conversas. Por otro lado, el rostro de la imagen presenta características animalescas como la nariz chata de cerdo, quizás una referencia al término peyorativo «marrano» hacia las familias de origen judío. Las joyas del busto, los pendientes y el collar simbolizan el decreto franciscano del pasado que insistía en que «las mujeres judías se vieran obligadas a usar aretes como signos de la diferencia judía; también comenzaron a asociar los adornos con el lujo, la lujuria y la prostitución» (Lipton 2008: 230). Quizás la imagen fuese un intento de Serrete de 
IISTA DE LOS AUTOS, QUE SE HAN IMPRESSO defde 18 . de Mayo del año de 1726 . hatts 21 . de Octubre de efte año de 1725 . que fe hallaràn en Libro junros en la Plazuela de la Calle de la Sarter en la Libreriia de Ifidro Jofeph Serrete. Son las figuientes.

Año de $172 \mathrm{I}$ :

Madrid 18. de Mayo.

Granada 30. de Noviembre.

Sevilla 14. de Dizienbre.

\section{Ano de 1722 .}

Madrid 22, de Febrero:

Sevilla 24. de Febrero.

Toledo 15. de Março

Cordova 12 . de Abril.

Murcia I7. de Mayo.

Mailorea 31. de Mayo.

Cuenca 19. de Jurio.

Sevilla s. de Julio.

Murcia 8. de Octubre.

Santiago 2 I. de Septiembre.

Cuenca 22, de Noviembre.

Sevilla 3o. de Noviembre.

Llerena 30. de Novienbre.

\section{A rio de 1723.}

Granada 31. de Enero.

Poema Hereyco al dicho Aufo.

Valencia 24. de Febrero.

7 oledo 24 . de Fcorero.

Barcelo a 3r. Le Enero.

Cuenca 21. de Fobrepo.

Coimbra I 4 . de Março

Murcia 1 3. de Mayo.

Sevilia 6. de Junio.

Valladolid 6. de Junißs

Zaragoza 6. de Juvio.

Cordova 13 . de funio.

Granada 20. de Juaio.

$$
\text { * * * }
$$

Llerena 26 . de Julio. Sevilla ro, de Agollo.

Toledo 28 . de Octubre:

Lisboa ra. de Octubrs.

Valladolid 24. de Octubre:

Granada 19. de Dizienbre:

Año de r724.

Madrid 20. de Fchrero.

Valladolid 12. de Março

Valencia 2. de Abrit.

Cordova 23. de Abril.

Scuilla xr. de Junio.

Granade 25 . de Junio:

Cordova 2, de jolio.

Mallorca 2. de fulio.

Cucnea 23 . de Julio.

Murcia 30. de Noviembre.

Santiago 9. de Noviembre.

Sevilla 21, de Dizicubre.

Liso de 1725 .

Cuenca ${ }^{4} 4$. de Encio.

Llerena 4. de Febrero.

Cuenca 4. de Matço.

Villadolid 5. de Março.

Granada I 3r de Mayo.

Toicto I. de Julio.

Valencia I. de Julio.

Valladulid 8, de Julio:

Granada 24 . de Ayolto.

Llerena 26. de Agofto.

Barcelona o.de Senciembre a

Murcia 2 I, de Octubre:

** *

**

[IMAGEN 1] Relacion de los Autos, particulares de Fee, que el Tribunal del Santo Oficio de la Inquisicion de Barcelona celebrò en la Iglesia del Convento de Santa Cathalina Martyr, Orden de Predicadores. (C) Biblioteca Nacional de España. 
atraer a más lectores o de satisfacer el «gozo» de sus seguidores ya que la ilustración aparece en varias relaciones de 1722 (en Murcia, Valladolid, Madrid y Sevilla). En cualquier caso, estos textos y sus imágenes reflejan las contradicciones de la iconografía inquisitorial sobre el cuerpo femenino y la violencia contra la mujer. A partir de 1723, el busto dejó de incluirse y se sustituyó por querubines o cabezas de ángeles con alas y vegetación que quizás la Inquisición consideró más apropiado para estos trabajos. Quizás el edicto de fe, escrito por el tribunal de Sevilla en nombre del Santo Oficio de 1726 que recordaba a los fieles la prohibición de estampas con dibujos inmorales influyó en dicha decisión. Después de todo, las relaciones de los autos de fe de Serrete fueron comisionadas por la Inquisición y la ilustración del busto femenino con los pechos descubiertos podría considerarse como una estampa lasciva, prohibida con pena de excomunión.

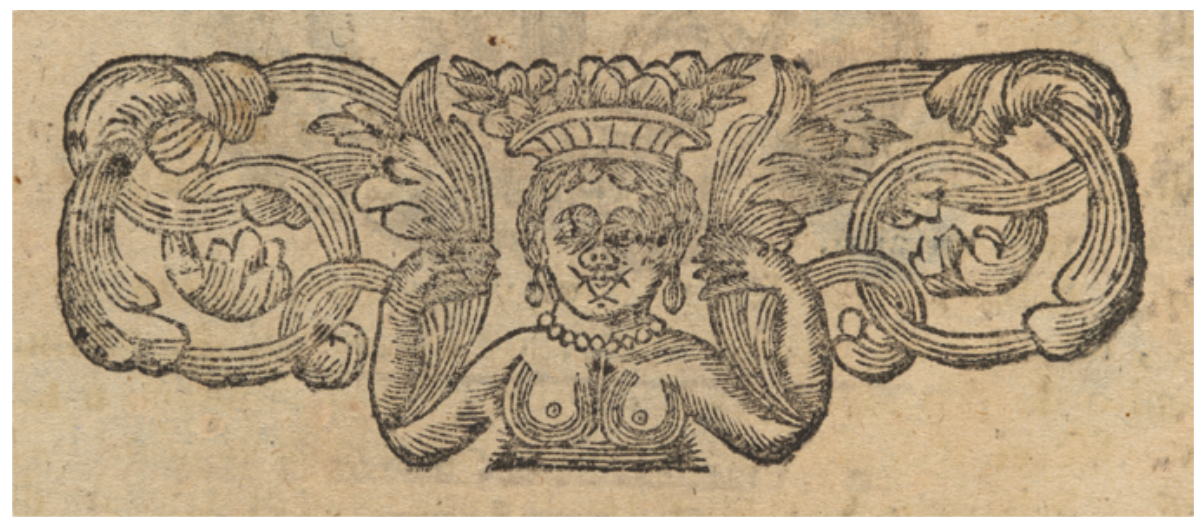

[IMAGEN 2] Relación del Auto de Fe celebrado en Sevilla el 14 de diciembre de 1721, p. 8. (Houghton Library, Harvard University).

Las relaciones de los autos de fe de Serrete dejaron de publicarse a mediados del siglo XVIII, aunque algunos manuscritos informales sobre autos de fe aislados siguieron produciéndose. La última persona asesinada por la Inquisición fue una mujer, Lucía González, en el auto de fe particular que se celebró en el convento de San Pedro Mártir en Toledo el 20 de marzo de 1738 (Caro Baroja 1978: 92). Era natural de Valladolid, era viuda y fue relajada a la justicia y brazo seglar por judaizante. Que sirva este trabajo como un homenaje hacia Lucía González y todas las mujeres criptojudías españolas, hacia su recuperación histórica y hacia la valoración de su posición de poder religioso, cultural y económico, por lo que fueron perseguidas por la Inquisición. 


\section{BIBLIOGRAFÍA}

Alpert, Michael (1997). «The secret Jews of $18^{\text {th }}$ Century Madrid». Revue des Études Juives, 15, pp. 135-171.

AlPERT, Michael (2001). Criptojudaísmo e Inquisición en los siglos XVII y XVIII. Barcelona: Ariel.

Anónimo (1723). Poema heroyco, a el auto particular de fé, que se celebró en la ciudad de Granada, el día 31 de enero deste presente año de 1723. Madrid: José Serrete.

Archivo Histórico Nacional (AHN - Madrid), Inq., leg. 160 exp. 11. Proceso de fe de Diego López de Castro Paz Coronel Quirós.

Archivo Histórico Nacional (AHN - Madrid), Inq., leg. 175, exp. 4. Proceso de fe de Agustina Juana Manuela Pimentel, natural del Puerto de Santa María y vecina de Madrid, hija del capitán de Infantería Antonio Pimentel y María Feliciana Hurtado de Mendoza, por judaizante.

Archivo Histórico Nacional (AHN - Madrid), Inq., leg. 186, exp. 3. Proceso de fe de Francisco de Torres, casado con Isabel de Rivera, vecino de Toledo, por judaizante.

Archivo Histórico Nacional (AHN - Madrid), Inq., leg. 3.736, exp. 68. Alegación fiscal del proceso de fe de Francisco González y Manuela Rico, su mujer, originarios de Madrid, seguido en el Tribunal de la Inquisición de Corte, por judaizantes.

Argulló y CoBo, Mercedes (1980). Madrid en 1714. Madrid: Ayuntamiento de Madrid/ Instituto de Estudios Madrileños.

Blázquez Miguel, Juan (1988). Inquisición y criptojudaísmo. Madrid: Ediciones Kaydeda.

Buitrago GonzÁlez, José Luis (2013). «Serranía críptica: la última gran persecución contra judaizantes en la España del siglo XvIII». Revista de la Inquisición, 17, pp. 1144.

Buitrago GonzÁlez, José Luis (2014). «El origen de los Juárez: los últimos criptojudíos perseguidos por la Inquisición española en el siglo XVIII». Historia y Genealogía, 4, pp. 179-192.

CARo Baroja, Julio (1978). Los judios en la España moderna y contemporánea. Madrid: Istmo.

Domínguez Ortiz, Antonio (1988). Los judeoconversos en España y América. Madrid: Istmo.

EgIDo LóPEZ, Teófanes (1984). «La Inquisición en la España borbónica, el declive del Santo Oficio (1700-1808). Los cambios en el Santo Oficio español: las modificaciones de la tipología, nueva estructura delictiva». En Bartolomé Escandell Bonet y Joaquín Pérez Villanueva (dirs.), Historia de la Inquisición en España y América, I. Madrid: Biblioteca de Autores Cristianos/Centro de Estudios Inquisitoriales, pp, 1.380-1.403.

GACто, Enrique (2000). «El Arte vigilado (Sobre la censura estética de la Inquisición española en el siglo XVIII)». Revista de la Inquisición, 9, pp. 7-68.

Galende Díaz, Juan Carlos (1988). «La Inquisición toledana desde la llegada de los Borbones (1700-1834)». Anales Toledanos, 25, pp. 245-284. 
Haliczer, Stephen (1990). Inquisition and Society in the Kingdom of Valencia 1478-1834. Berkeley/Los Angeles: University of California Press.

Hinojosa Montalvo, José (1992). «La sociedad y la economía de los judíos en Castilla y la Corona de Aragón durante la Baja Edad Media». En II Semana de Estudios Medievales: Nájera, 5 al 9 de agosto de 1991. Logroño: Instituto de Estudios Riojanos, pp. 79-109.

Kamen, Henry (1979). La Inquisición española. Barcelona: Crítica.

LERA GARCía, Rafael de (1987). «La última gran persecución inquisitorial contra el criptojudaísmo. El tribunal de Cuenca. 1718-1725». Sefarad: Revista de Estudios Hebraicos y Sefardies, 47 (1), p. 87-137.

LERA García, Rafael de (1989). «Gran ofensiva antijudía de la inquisición de Granada 1715-1727». Chronica Nova: Revista de Historia Moderna de la Universidad de Granada, 17, pp. 147- 169.

Levine Melammed, Renée (1999). Heretics of Daughters of Israel? The Crypto-Jewish Women of Castile. New York: Oxford University Press.

Lipton, Sara (2008). «Where are the Gothic Jewish Women? On the Non-Iconography of the Jewess in the Cantigas de Santa María». Jewish History, 22, 1/2, pp. 139-177.

Llorente, Juan Antonio (1980). Historia crítica de la Inquisición en España. Madrid: Hiperión.

LóPEZ Belinchón, Bernardo José (2014). «Los últimos conversos. Represión, memoria y conversos en el siglo XVIII». Atalaya, $14<\mathrm{http}$ ://journals.openedition.org/atalaya/ 1311> [Consulta: 04/06/2019].

LóPEZ-VIDRIERo, María Luisa (1994). «La imprenta en el siglo XVIII». En Hipólito Escolar (ed.), De los incunables al siglo XVIII. Madrid: Biblioteca del Libro, pp. 201-269.

Madrigal CAstro, Sara (2017). «La reacción anticonversa del reinado de Felipe V. Los judaizantes de Cantillana». Revista de la Inquisición: Intolerancia y Derechos $\mathrm{Hu}$ manos, 21, pp. 135-144.

Martínez Millán, José (1989). «La persecución inquisitorial contra los criptojudíos a principios del siglo XVIII. El tribunal de Murcia (1715-1725)». Sefarad: Revista de Estudios Hebraicos y Sefardies, 49, 2, pp. 307-363.

Moya Torres y Velasco, Francisco Máximo de (1992). Manifiesto universal de los males envejecidos que España padece [1730]. Antonio Domínguez Ortiz (ed.). Madrid: Sociedad Estatal Quinto Centenario.

Peñafiel Ramón, Antonio (1992). «Reductos judaizantes en el siglo XVIII. El Tribunal del Santo oficio de Murcia». Revista de la Inquisición: Intolerancia y Derechos $\mathrm{Hu}$ manos, 2, pp. 49-70.

Pérez de Colosía Rodríguez, María Isabel (2005). «Mujeres procesadas por el Tribunal del Santo Oficio de Granada». Baética: Estudios de Arte, Geografia e Historia, 27, pp. 423-436.

Prado Moura, Ángel de (1996). Las hogueras de la intolerancia. La actividad represora del Tribunal Inquisitorial de Valladolid (1700-1834). Valladolid: Junta de Castilla y León. 
Relación de las personas que salieron a el auto particular de fe, que celebró el Santo Oficio de la Inquisición de Toledo en el Real Convento de San Pedro Martyr de aquella ciudad, Orden de Predicadores, el día 20 de marzo de este presente año de 1738. Toledo: Joseph de Cueñas, 1738.

Relación de las personas, que salieron en el auto de fè particular, celebrado el domingo quinze de março este año de 1722. en la iglesia del Convento de San Pedro Martyr, Orden de Predicadores de la ciudad de Toledo. Madrid: Isidro Joseph Serrete, 1722.

Relación de los autos particulares de fe que se han celebrado en las Inquisiciones de Valladolid, en la Iglesia Parroquial del Señor San Pedro, el dia 24 de agosto de este presente año de 1722, y la de Zaragoza, en la Iglesia del Real Convento del Serafico Padre San Francisco, domingo 11 de octubre de dicho año. Madrid: Isidro Joseph Serrete, 1722.

Relación de los autos particulares de fe que se han celebrado en las inquisiciones de Granada, el día nueve de mayo en la iglesia de el Convento de Mercenarios Calçados: y en la de Sevilla el mismo día nueve, en la capilla de San Jorge de dicha Inquisición. Madrid: Andrés Sánchez, 1727.

Relación de los autos particulares de fe, que se han celebrado en las Inquisiciones de Cuenca, el día del apóstol San Pedro 29 de junio de este año de 1722 en la iglesia del Convento de San Pablo, Orden de Predicadores de dicha ciudad y la de Mallorca. Madrid: Isidro Joseph Serrete, 1722.

Relación de los autos particulares de fe, que se han celebrado en la inquisición de Valladolid, en la iglesia del convento de San Pablo, orden de Santo Domingo, el domingo día de la Santissima Trinidad, 13 de junio y en la de Granada en la iglesia parroquial del Señor Santiago de aquella ciudad el día 4 del presente mes de julio, y ambos en este presente año de 1745. Madrid: Manuel López, 1745.

Relación de los autos particulares de fé, que se han celebrado en las inquisiciones de Cordova el día 15 de mayo, en la capilla de San Acazio, de los reales alcázares de dicha ciudad. Y en la de Granada el día diez de octubre en la iglesia del convento. Madrid: Isidro Joseph Serrete, 1728.

Relación de los reos que salieron en el Auto Particular de Fe que celebró el santo oficio de la Inquisición de Granada el día veinte de junio de mil setecientos y veinte y tres, en el Convento de Nuestra Señora de la Merced, de Calzados, de dicha Ciudad. Madrid: Isidro Joseph Serrete, 1723.

Relación de los reos, que salieron el auto particular de fé, que el Tribunal del Santo Oficio de la Inquisición de esta Corte [de Madrid] celebró en la iglesia del religiosísimo Convento de Santo Domingo el Real, la dominica primera de cuaresma, 22, de este presente mes de febrero. Madrid: Isidro Joseph Serrete, 1722.

Relación de los reos, que salieron en el auto particular de fe, que el tribunal del Santo oficio celebró el día veinte y quatro de febrero, en la parroquia de Santa Ana del Varrio de Triana de la ciudad de Sevilla, este año de 1722. Madrid: Isidro Joseph Serrete, 1722.

Relación del auto de fe que el domingo 7 de abril de 1720, se celebró en esta corte de Madrid en el Convento de Santo Domingo. Madrid, 1720. BNE ms. 9.304. 
Relación del auto de fe que el tribunal del Santo Oficio de la Inquisición de Murcia, celebró en el Convento de San Francisco de dicha ciudad, el Domingo diez y siete de mayo de este año de 1722. Madrid: Isidro Joseph Serrete, 1722.

Relación del auto particular de fe, que celebró el Santo oficio de la Inquisición de esta ciudad y reinado de Sevilla domingo 14 de diciembre de este presente año de 1721 en la iglesia del real convento de San Pablo, Orden de predicadores. Madrid: Isidro Joseph Serrete, 1721.

Relación del auto particular de fe, que celebró el Santo Oficio de la Inquisición de la ciudad, y reyno de Granada, el día 30 de noviembre de este presente año de 1721 en la iglesia del Real Monasterio de S. Gerónimo desta dicha ciudad. Granada: Nicolás Rodríguez Francos, 1721.

Relación del auto particular de fe, que el Santo Oficio de la Inquisición de Valladolid celebró el domingo 26 de enero de este año de 1727 en la Iglesia parroquial del señor San Pedro de dicha ciudad. Madrid: Isidro Joseph Serrete, 1727.

Rodríguez Gordillo, José M. (2002). La Creación del estanco de tabaco en España. Madrid: Altadis.

Rоoтн, Cecile (1979). Los judios secretos. Historia de los marranos. Madrid: Altalena.

Rubin, Miri (1999). Gentile Tales. The Narrative Assault on Late Medieval Jews. New Haven: Yale University Press.

Torres Arce, Marina (2003). «Los judaizantes y el Santo oficio de Logroño en el reinado de Felipe V». En Bartolomé Escandell Bonet y Joaquín Pérez Villanueva (dirs.), Historia de la Inquisición en España y América. Madrid: Biblioteca de Autores Españoles/Centro de Estudios Inquisitoriales, III, pp. 657-694.

Recibido: 26/07/2019

Aceptado: 30/08/2019 


\section{雾}

LAS MUJERES CRUPTOJUDÍAS EN LA PRIMERA MITAD DEL SIGLO XVIII: RECUPERACIÓN HISTÓRICA E INQUISICIÓN

RESUMEN: Entre 1700 y 1758, alrededor de 800 mujeres fueron castigadas por practicar la ley de Moisés en España. Consideramos por ello importante estudiar el papel de las mujeres criptojudías en el contexto histórico de la primera mitad del siglo XVIII para poder investigar las razones por las que la Inquisición las consideró como su principal amenaza y objetivo de persecución. En un principio, se dará un breve contexto político-cultural de las primeras décadas del siglo XVIII para entender el porqué del despertar del acoso inquisitorial contra las culturas criptojudías. De ahí, se señalará la importancia de las mujeres en dicho ámbito para luego pasar al estudio de los autos de fe, la presencia de las mujeres en dichos procesos y el poder propagandístico de las publicaciones de los autos de fe en forma de relaciones.

PALABRAS CLAVE: mujeres criptojudías, criptojudaísmo, Inquisición, antisemitismo, autos de fe, xenofobia.

\section{CRIPTO-JEWISH WOMEN IN THE FIRST HALF OF THE $18^{\text {TH }}$ CENTURY: HISTORICAL RECOVERY AND INQUISITION}

ABSTRACT: Between 1700 and 1758, about 800 women were punished for practicing the law of Moses in Spain. This article shall study the role of the crypto-Jewish women in the historical context of the first half of the $18^{\text {th }}$ century in order to investigate the reasons why the Inquisition considered them as their main threat and objective of persecution. Initially, this paper will offer a brief political-cultural context of the first decades of the $18^{\text {th }}$ century to understand the reasons of the awakening of inquisitorial harassment against crypto-Jewish cultures. Hence, this study will focus on the importance of women in crypto-Jewish cultures and will study the public trials, the presence of women in them and the propaganda power of the publications of the trials in the form of news pamphlets. KEYwords: crypto-Jewish women, cryptojudaism, Inquisition, anti-Semitism, autos de fe, xenophobia. 